

Journal of Aviation Technology and Engineering 8:2 (2019) 8-23

\title{
Collaborative Product-Service Approach to Aviation Maintenance, Repair, and Overhaul. Part II: Numerical Investigations
}

\author{
Cassio Dias Goncalves and Michael Kokkolaras
}

McGill University

\begin{abstract}
This two-part paper proposes a new collaborative approach to airframe maintenance, repair, and overhaul (MRO). A quantitative model is introduced in Part I to represent the business relationships between original equipment manufacturers (OEMs) and MRO enterprises. In Part II, the presented model is used to assess potential financial benefits obtained by each of these stakeholders as a result of the collaboration.

The quantitative model is built to capture the main dependencies between an independent MRO operating in South America and its interactions with three major airframe OEMs. Interviews were conducted with MRO and OEM professionals to identify the most impactful operational resources on MRO activities. Stakeholders with different characteristics in terms of production capacity, annual revenue, fleet size, and age are considered in the numerical studies to quantify the viability of the proposed collaborative business model in different scenarios.

The obtained results show that optimal investment levels must be determined for each stakeholder to ensure the viability of the proposed collaborative business model, confirming the need for a quantitative method to aid service designers making decisions.

This collaborative model contributes to the relatively scarce literature on the topic and promotes effective and structured collaboration between OEMs and MRO enterprises aiming at delivering higher added value to customers (operators).
\end{abstract}

Keywords: airframe maintenance, repair, and overhaul, product-service design, collaborative business model

\section{Introduction}

In the companion of this paper (Part I), we introduced a quantitative model that represents the business relationships between airframe original equipment manufacturers (OEMs) and independent aviation maintenance, repair, and overhaul (MRO) companies in order to assess the viability of a collaborative business approach to airframe service.

In the context of a growing MRO market driven by aircraft operators' shift from in-house maintenance to outsourced solutions (Federal Aviation Administration, 2013; Rosenberg, 2004), our quantitative model was built with the aim of fostering collaborative and sustainable business approaches between manufacturers and service providers. This model is intended to be a decision-making support tool that delivers additional value to aircraft operators. Vieira and Loures (2016) observe a tendency within the MRO market of building up partnerships between stakeholders. The collaborative approach proposed herein introduces the idea that OEMs and MRO enterprises should exchange product and in-service data, 
and share operational resources in order to reduce their risk of business failure, while delivering high-level services to operators (Goncalves \& Kokkolaras, 2017).

For example, OEMs could assume the responsibility of providing special tools to partner MRO companies, ensuring these resources would be readily available whenever required. Considering that OEMs have business relations with several MRO firms around the globe (PIPAME, 2010), the worldwide utilization level of those special tools would certainly be much higher than if the MRO firm were to buy them for its own usage, therefore justifying the investment made by OEMs. In this case, OEMs could charge a symbolic rental charge to MRO companies, or depending on the agreement, the tool could be borrowed by MRO firms free of charge. This may sound unacceptable for OEMs at a first glance, but putting this rental cost in perspective against the value generated to the customer and the benefits that OEMs could receive from MRO firms in the form of something like in-service data, then this cost may not turn out to be significant. This assumption is confirmed by the results presented in this paper, demonstrating that OEM investments have an insignificant negative impact on their gross profit (GP) while having a significant positive impact on MRO companies' GP, as well as on operators' savings. The negative impact on OEMs' GP is likely to be compensated for by the positive financial results obtained from in-service data collection and enhanced parts demand forecast.

It is valid to state, then, that the success of business relationships between these stakeholders is strongly dependent on the design quality of these relations (Kurita, Uei, Kimita, \& Shimomura, 2012). Wallin (2013) noted that collaboration across the supply chain is fundamental to the process of creating more robust product-service business models. In this ambit, a good design is one that considers the needs and interests of all stakeholders. It is evident that current manufacturers have been showing a unilateral design mindset, meaning that they only consider their own interests when assessing the economic feasibility of service design. They neglect observing the product-service system (PSS) as a whole, including other stakeholders' interests.

Within this context, this paper intends to demonstrate the practical application and value of the quantitative model as a design tool to support developing collaborative aviation product-service business models. It constitutes a quantitative means to assess the economic feasibility of relations between MRO firms and airframe OEMs.

\section{Configuration of Numerical Studies}

The numerical studies aim to demonstrate that the quantitative model presented in the companion (Part I) of this paper can be used as a tool to aid OEMs and MRO firms in building collaborative business strategies. With such strategies, maintenance providers can benefit from reduced expenditures in operational resources, operators can profit from reduced maintenance turn-around times (TATs), and manufacturers can benefit from in-service data collection, which improves their product reliability (Canaday, 2016) and reduces inventory costs.

The proposed PSS business model is composed of three main stakeholders: an MRO company, an OEM, and an operator. In this section, "what if?" scenarios are created in order to investigate how model outputs vary when the size and operational capacity of the stakeholders change and the monetary amounts invested by the OEM and the MRO vary. Two distinct configurations are proposed and listed in Table 1, which will be referred to as PSS1 and PSS2.

Additional parameter values have to be chosen in the model. Real data from an independent MRO in South America and its customers' fleets have been used to select the values of the first configuration. For the second configuration, parameter values were estimated by MRO experts. They are grouped in five categories and are described in the following sections (Goncalves \& Kokkolaras, 2017):

1. Product data.

2. In-service data.

3. Spare parts.

4. Tooling.

5. Training.

Estimated values were reviewed by six MRO and OEM professionals:

1. Engineering/planning manager with 17 years of experience in MRO operations in Argentina and Brazil.

2. Quality and regulations manager with more than 30 years of experience in the international MRO sector, as well as in a large airframe OEM in South America.

3. Maintenance manager with 18 years of experience in airframe OEMs and MROs in North America and South America.

4. MRO specialist with 16 years of experience from a major European OEM located in Spain.

Table 1

Parameter values for two configurations PSS1 and PSS2.

\begin{tabular}{llcc}
\hline Parameter & Description & PSS1 & PSS2 \\
\hline$G P_{\text {OEM }}$ & OEM's annual gross profit & $\$ 1 \mathrm{~B}$ & $\$ 1 \mathrm{~B}$ \\
$G P_{M R O}$ & MRO firm's annual gross profit & $\$ 3 \mathrm{M}$ & $\$ 500 \mathrm{M}$ \\
$N H C_{\text {year }}$ & MRO firm's capacity in numbers of heavy checks per year of a four-year-old B737NG & 50 & 500 \\
$F H Y_{\text {perAC }}$ & Aircraft average flight hours per year & 3000 & 3000 \\
OFS & Operator's fleet size & 12 & 120 \\
\hline
\end{tabular}


5. CEO of an MRO in Brazil with more than 35 years of experience in aviation.

6. Maintenance supervisor from Chile with more than 30 years of MRO experience

\section{Model Parameters}

\section{Product Data Parameters}

Product data such as component maintenance manuals (CMM), service bulletins (SB), drawings, and diagrams, etc., represent fundamental resources for the execution of preventive and corrective maintenance. Any maintenance task performed on an aircraft must comply with instructions given in the technical publications of the manufacturer. Lack of technical instructions during maintenance activities leads to the interruption of the task. The first author's years of experience in the airframe maintenance industry suggest that such cases of interruptions may occur often because the required publications are not always available in a timely fashion, obliging the MRO to start a last-minute procurement process.

Values expressed in Table 2 are estimated by MRO subject matter experts (SMEs); they take into account historical data of cost and time to acquire the relevant resources. Acquisition involves processes such as supplier contact and request, purchasing, payment processing, and import processing.

The values for the product data parameters do not vary from configuration one to configuration two since the times for resource acquisition are considered to be a market average, and the required amount of investment in subscriptions does not vary with the size of the MRO firm.

\section{In-Service Data Parameters}

Maintenance intervals data are specified by manufacturers and published in a technical manual called maintenance plan data, which is specific to aircraft type. For example, the Boeing aircrafts B727-200 and B737-300 have different maintenance plans and thus distinct maintenance time intervals (McLoughlin, Doulatshahi, \& Onorati, 2011). Other parameters, such as the average downtime for a C-check (heavy check) and number of maintenance reports generated per aircraft, depend not only on the type in most cases, but also on the age of the aircraft considered. The older the aircraft, the higher the likelihood of finding discrepancies during inspections, thus the number of maintenance reports may be higher and the amount of downtime may be longer. In this case, the values of in-service data parameters do not vary from configuration one to configuration two since both configurations consider the same type and age of aircraft. The type of aircraft and check considered in this study are B737NG and C-check, respectively. The average fleet age is considered to be four years old (see Table 3 for in-service parameters).

\section{Spare Parts Data Parameters}

Spare parts are certainly one of the most critical resources in the independent MRO business. Aircraft parts are always quite expensive, so inventory cannot be kept at high levels in a maintenance provider's warehouse (Cohen \& Wille, 2006; SAS Institute, 2014). The solution is either

Table 2

Product data-related parameters.

\begin{tabular}{|c|c|c|c|}
\hline Parameter & Description & PSS1 & PSS2 \\
\hline$L T_{i d_{\text {avg }}}$ & Average acquisition time of an installation drawing & 3 days & 3 days \\
\hline$L T_{f d_{a v g}}$ & Average acquisition time of a fabrication drawing & 3 days & 3 days \\
\hline$L T_{c m m_{a v g}}$ & Average acquisition time of a CMM & 2 days & 2 days \\
\hline$L T_{s b_{\text {avg }}}$ & Average acquisition time of a SB & 2 days & 2 days \\
\hline$I R_{i d}$ & Required annual investment in installation drawings in order to have zero gap & $\$ 5,000$ & $\$ 5,000$ \\
\hline$I R_{f d}$ & Required annual investment in fabrication drawings in order to have zero gap & $\$ 10,000$ & $\$ 10,000$ \\
\hline$I R_{c m m}$ & Required annual investment in CMMs in order to have zero gap & $\$ 5,000$ & $\$ 5,000$ \\
\hline$I R_{s b}$ & Required annual investment in SBs in order to have zero gap & $\$ 5,000$ & $\$ 5,000$ \\
\hline
\end{tabular}

Table 3

In-service data-related parameters.

\begin{tabular}{|c|c|c|c|}
\hline Parameter & Description & Value & Source \\
\hline$M M I_{a v g / h c}$ & The considered average maintenance interval for a C-check. Depends on the type of aircraft. & $6,000 \mathrm{FH}$ & Ali and McLoughlin (2012) \\
\hline$M D T_{a v g / h c}$ & The market average aircraft downtime for a C-check of that specific aircraft model and age. & $12 \mathrm{~d}$ & Estimate from MRO SMEs \\
\hline$M D T_{h c}$ & $\begin{array}{l}\text { The acceptable downtime for a C-check of that specific aircraft model and age as per } \\
\text { operator's needs. There are some cases where a particular operator can accept a downtime } \\
\text { different from the market average. }\end{array}$ & $15 \mathrm{~d}$ & Estimate from MRO SMEs \\
\hline$L D C$ & The aircraft leasing cost per day, if applicable & $\$ 20,000$ & Operator data \\
\hline$N R_{\text {AC/year }}$ & $\begin{array}{l}\text { The estimated number of maintenance reports generated by one aircraft in a one-year time span } \\
\text { (model of aircraft and type of operation). }\end{array}$ & 400 reports & Estimate from MRO SMEs \\
\hline
\end{tabular}


being able to make urgent purchases or utilizing a local supplier.

Lack of parts leads to interruption of maintenance activities, which can often impact the aircraft TAT. Values expressed in Table 4, like the values expressed in Table 2, are estimated by SMEs from an MRO in South America and take into account historical data of cost and time to acquire those parts, which involves processes such as procurement, purchasing, payment processing, and import processing.

The following classification of spare parts is adapted from the International Air Transport Association (IATA, 2015) where spare parts are originally classified as rotable, repairable, and expendable, depending on criteria such as scrap rate, cost, or life-cycle. In the scope of this research, consumable is introduced, expendable is subdivided in two types, and repairable is considered as being the same as rotable.

The value of a TAT increase resulting from a missing part is calculated as the difference between the acquisition time of that unplanned resource (including procurement time, import time, transportation, and utilization) and the time originally planned for the rectification phase of the $\mathrm{C}$-check (see Figure 1 for the conceptual phases of a heavy check considered in the context of this research).
The average acquisition time of the unplanned resources, used to calculate the TAT increase, was estimated by the parts procurement SME and confirmed by the purchasing department's historical data of the referred MRO (see Table 6). That type of information (also called logistic lead times) is recorded and stored in the material and resources planning system of the company. The planned time of the maintenance phases is estimated by the planning department SME and is related to a C-check of a Boeing $737 \mathrm{NG}$ aircraft.

\section{Tooling Data Parameters}

Similar to spare parts data parameters, values expressed in Table 5 are estimated by SMEs from an MRO in South America and take into account historical data of cost and time to acquire these equipment and tools, which involve processes such as procurement, purchasing, payment processing, and import processing.

The value of a TAT increase resulting from a missing tool is calculated following the same rationale used for spare parts. It is the difference between the time for acquisition of that unplanned tool (including procurement time, import time, transportation, and utilization) and the time originally planned for the rectification phase of the C-check.

Table 4

Spare parts data-related parameters.

\begin{tabular}{llcc}
\hline Parameter & Description & PSS1 & PSS2 \\
\hline$I R$ & The interest rate & $5 \%$ & $5 \%$ \\
$T I_{\text {cp }_{\text {avg }}}$ & The average TAT increase (days) due to lack of a consumable part & 0 days & 1 day \\
$T I_{\text {lep }}$ & The average TAT increase (days) due to lack of a light expendable part & 4 days & 1 days \\
$T I_{\text {hep }}$ & The average TAT increase (days) due to lack of a heavy expendable part & 1.5 days & 4 days \\
$T I_{\text {rot }}$ & The average TAT increase (days) due to lack of a rotable part & $\$ 50,000$ & 1.5 days \\
$I R_{c p}$ & The required investment in consumable parts in order to have zero gap & $\$ 100,000$ & $\$ 500,000$ \\
$I R_{\text {lep }}$ & The required investment in light expendable parts in order to have zero gap & $\$ 3 \mathrm{M}$ & $\$ 1000,000$ \\
$I R_{\text {hep }}$ & The required investment in heavy expendable parts in order to have zero gap & $\$ 6 \mathrm{M}$ & $\$ 30 \mathrm{M}$ \\
$I R_{\text {rot }}$ & The required investment in rotable parts in order to have zero gap & $\$ 60 \mathrm{M}$ \\
\hline
\end{tabular}

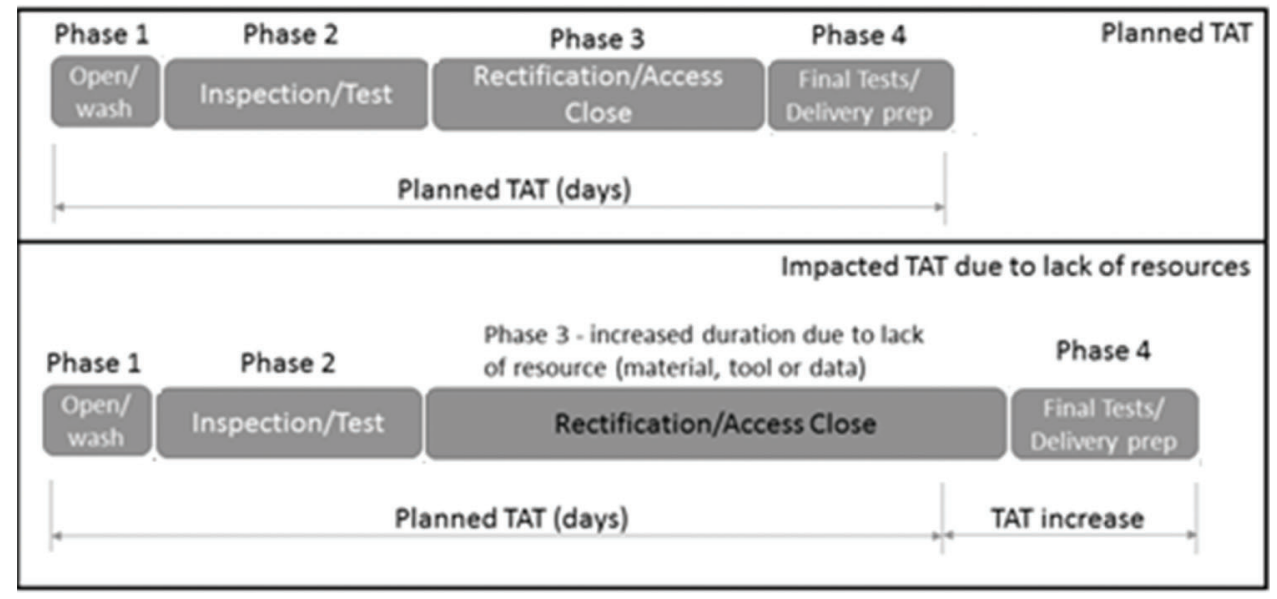

Figure 1. Impact on TAT due to lack of resources (Goncalves and Kokkolaras, 2017). 
Table 5

Tooling-related parameters.

\begin{tabular}{|c|c|c|c|}
\hline Parameter & Description & PSS1 & PSS2 \\
\hline$T I_{N D I_{\alpha v g}}$ & The average TAT increase (days) due to the lack of non-destructive inspection (NDI) equipment & 1 day & 1 day \\
\hline$T I_{h c_{a v g}}$ & The average TAT increase (days) due to the lack of a hydraulic cart & 3.5 days & 3.5 days \\
\hline$T I_{s t_{\text {avg }}}$ & The average TAT increase (days) due to the lack of special tools & 1 day & 1 day \\
\hline$T I_{t s_{\text {avg }}}$ & The average TAT increase (days) due to the lack of a test set & 3.5 days & 3.5 days \\
\hline$T I_{s j_{\text {avg }}}$ & The average TAT increase (days) due to the lack of a special jig & 2 days & 2 days \\
\hline$I R_{N D I}$ & The required investment in NDI equipment in order to have zero gap & $\$ 50,000$ & $\$ 500,000$ \\
\hline$I R_{h c}$ & The required investment in a hydraulic cart in order to have zero gap & $\$ 250,000$ & $\$ 2,500,000$ \\
\hline$I R_{s t}$ & The required investment in special tools in order to have zero gap & $\$ 80,000$ & $\$ 800,000$ \\
\hline$I R_{t s}$ & The required investment in test sets in order to have zero gap & $\$ 250,000$ & $\$ 2,500,000$ \\
\hline$I R_{s j}$ & The required investment in special jigs in order to have zero gap & $\$ 350,000$ & $\$ 3,500,000$ \\
\hline
\end{tabular}

Table 6

Spare parts and tools acquisition data and related TAT increase calculation.

\begin{tabular}{|c|c|c|c|}
\hline Type of resource & Acquisition time & Phase 3 planned duration & TAT increase \\
\hline \multicolumn{4}{|l|}{ Tools and equipment } \\
\hline NDI equipment & 5 days & 4 days & 1 days \\
\hline Hydraulic cart & 7.5 days & 4 days & 3.5 day \\
\hline Special tools & 5 days & 4 days & 1 days \\
\hline Test sets & 7.5 days & 4 days & 3.5 days \\
\hline Special jigs & 6 days & 4 days & 2 days \\
\hline \multicolumn{4}{|l|}{ Spare parts } \\
\hline Consumable parts & 2 days & 4 days & 0 days \\
\hline Light expendable parts & 5 days & 4 days & 1 day \\
\hline Heavy expendable parts & 8 days & 4 days & 4 days \\
\hline Rotable parts & 5.5 days & 4 days & 1.5 days \\
\hline
\end{tabular}

Table 7

Training data-related parameters.

\begin{tabular}{|c|c|c|c|}
\hline Parameter & Description & PSS1 & PSS2 \\
\hline$I R_{t r}$ & Required annual investment in training in order to have zero gap & $\$ 100,000$ & $\$ 1 \mathrm{M}$ \\
\hline$T A T_{o p t}$ & Optimum TAT (considering $100 \%$ resources available) & 10 days & 10 days \\
\hline
\end{tabular}

The average acquisition time of the unplanned tool, used to calculate the TAT increase, was estimated by the procurement SMEs and also confirmed by the purchasing department's historical data of the referred MRO (see Table 6). The planned time of the maintenance phases is estimated by the planning department SME and is related to a C-check of a Boeing 737NG aircraft.

\section{Training Data Parameters}

Physical resource availability, such as availability of spare parts and tools, does not ensure good quality and efficient maintenance services in MRO companies without highly skilled personnel assigned to the related maintenance tasks (Dinero, 2005). The amount of training given to the MRO's maintenance personnel has a direct impact on the company's productivity and on TAT variations of the maintenance services. In addition, certified maintenance service providers must comply with international aviation regulations by developing and executing their internal training programs to ensure that technical personnel are properly qualified to meet adequate standards. In this paper, the amount of training given to maintenance technicians is defined as a required resource.

The values of investment required in technical and non-technical training (Table 7) are estimated by MRO training SMEs (like training instructors) for configurations one and two based on the company's historical cost data with training. The optimal TAT value is also estimated by the company's SMEs based on market practices and is related to a C-check of a four-year-old Boeing B737NG aircraft.

\section{Numerical Results}

\section{Impact on Gross Profit}

The first analysis assesses the impact on the OEM's and the MRO's GP caused by different levels of investments from each of them. In that sense, three investment scenarios have been considered:

1. The OEM makes $100 \%$ of the PSS-required investments. 
2. The OEM makes $50 \%$ of the PSS-required investments and the MRO makes the other $50 \%$.

3. The OEM makes $80 \%$ of the PSS-required investments and the MRO makes the remaining $20 \%$.

In addition, the effect on total operator savings is also quantified against the variation of the source of investment.

For each of the three scenarios, value ranges are defined for the input variables of configuration one and configuration two, as listed in Table 8.

The results obtained by exercising the quantitative model presented in the companion (Part I) of this paper are depicted in Figures 2-7.

Based on these results, we can draw the following conclusions:

1. The first $(100 \%$ investment from OEM) and third (80\% investment from OEM and $20 \%$ investment from MRO firm) scenarios are the most attractive for MRO companies. In the second scenario (50/50 investment), the MRO firm's IGP is always $0 \%$ as the impact on its GP is calculated as the difference between investments made by the OEM and investments made by the MRO.

2. Investments made by the OEM usually have an insignificant negative impact on its GP, but a significant positive impact on the MRO firm's GP as well as on operators' savings. The negative impact on the OEM's GP can be compensated for by the financial benefits of getting in-service data (enhancing parts demand forecast). As an example, with an investment of $\$ 6 \mathrm{M}$ for scenario $3(80 / 20)$, the OEM's impact on GP is $0.07 \%$ against the MRO firm's impact of $7 \%$ (100 times difference), while operators' savings are of the order of $\$ 200,000$.

Table 8

Value range for investment input variables.

\begin{tabular}{|c|c|c|c|c|}
\hline & \multicolumn{2}{|c|}{ PSS1 } & \multicolumn{2}{|c|}{ PSS2 } \\
\hline & Min. investment & Max. investment & Min. investment & Max. investment \\
\hline \multicolumn{5}{|l|}{ Product data } \\
\hline Installation drawings & $\$ 500$ & $\$ 5,000$ & $\$ 500$ & $\$ 5,000$ \\
\hline Fabrication drawings & $\$ 1,000$ & $\$ 10,000$ & $\$ 1,000$ & $\$ 10,000$ \\
\hline CMM & $\$ 500$ & $\$ 5,000$ & $\$ 500$ & $\$ 5,000$ \\
\hline SB & $\$ 500$ & $\$ 5,000$ & $\$ 500$ & $\$ 5,000$ \\
\hline \multicolumn{5}{|l|}{ Spare parts } \\
\hline Consumables & $\$ 5,000$ & $\$ 50,000$ & $\$ 50,000$ & $\$ 500,000$ \\
\hline Light expendables & $\$ 10,000$ & $\$ 100,000$ & $\$ 100,000$ & $\$ 1000,000$ \\
\hline Heavy expendables & $\$ 300,000$ & $\$ 3 \mathrm{M}$ & $\$ 3,000,000$ & $\$ 30 \mathrm{M}$ \\
\hline Rotables & $\$ 600,000$ & $\$ 6 \mathrm{M}$ & $\$ 6,000,000$ & $\$ 60 \mathrm{M}$ \\
\hline \multicolumn{5}{|l|}{ Tooling } \\
\hline NDI & $\$ 5,000$ & $\$ 50,000$ & $\$ 50,000$ & $\$ 500,000$ \\
\hline Hydraulic cart & $\$ 25,000$ & $\$ 250,000$ & $\$ 250,000$ & $\$ 2,500,000$ \\
\hline Special tools & $\$ 8,000$ & $\$ 80,000$ & $\$ 80,000$ & $\$ 800,000$ \\
\hline Test sets & $\$ 25,000$ & $\$ 250,000$ & $\$ 250,000$ & $\$ 2,500,000$ \\
\hline Special jigs & $\$ 35,000$ & $\$ 350,000$ & $\$ 350,000$ & $\$ 3,500,000$ \\
\hline \multicolumn{5}{|l|}{ Training } \\
\hline Technical and non-technical & $\$ 10,000$ & $\$ 100,000$ & $\$ 100,000$ & $\$ 1,000,000$ \\
\hline
\end{tabular}

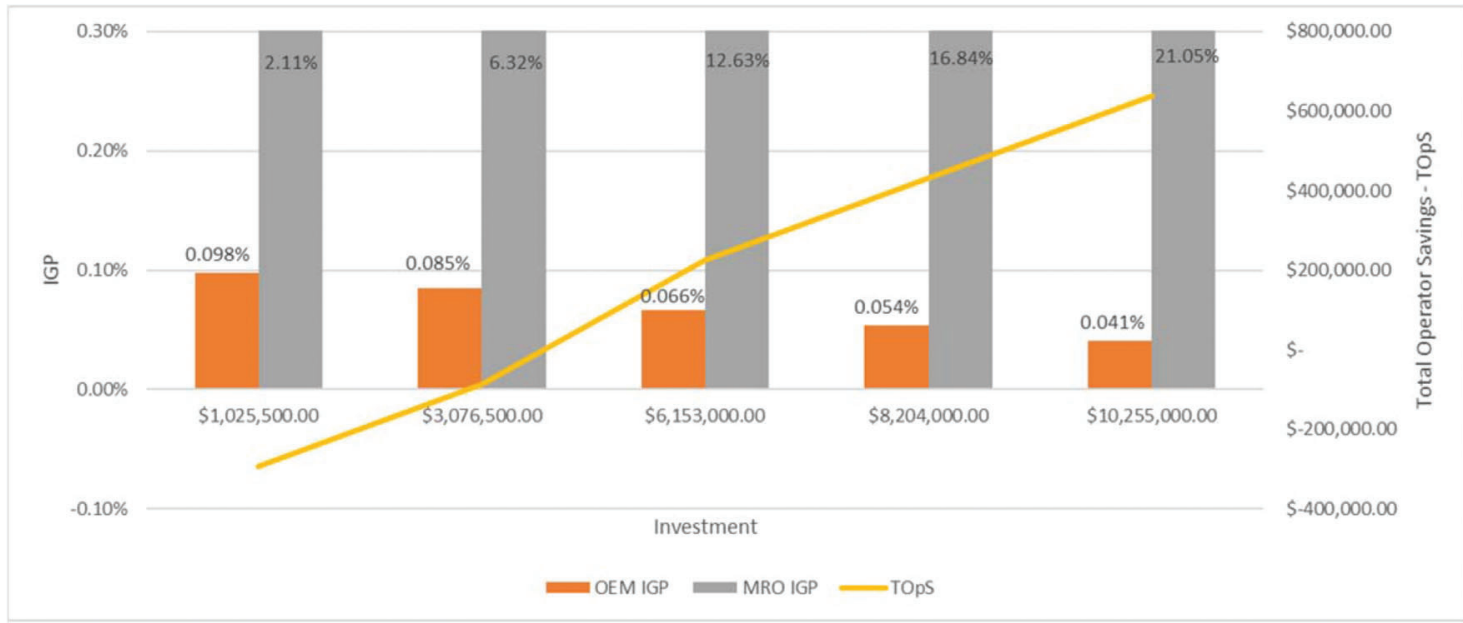

Figure 2. PSS1 impact on GP versus total operator savings (100\% investment from OEM). 


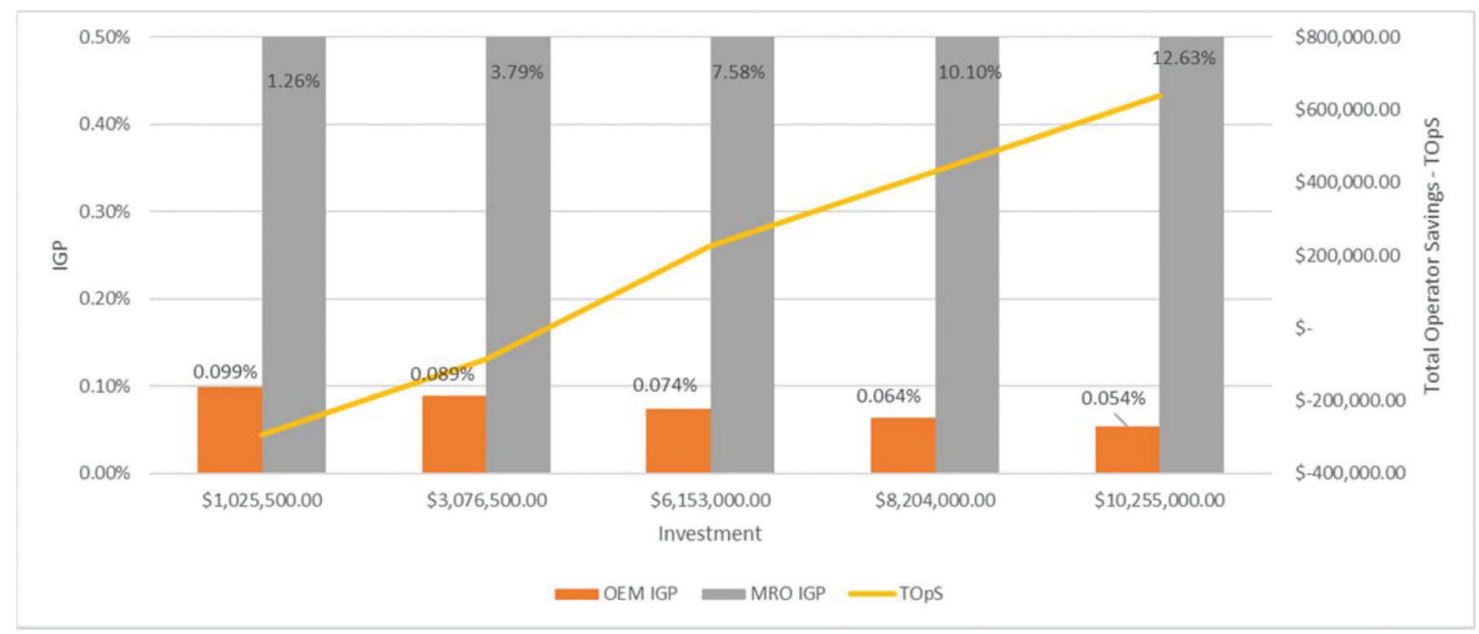

Figure 3. PSS1 impact on GP versus total operator savings (80\% investment from OEM and 20\% investment from MRO firm).

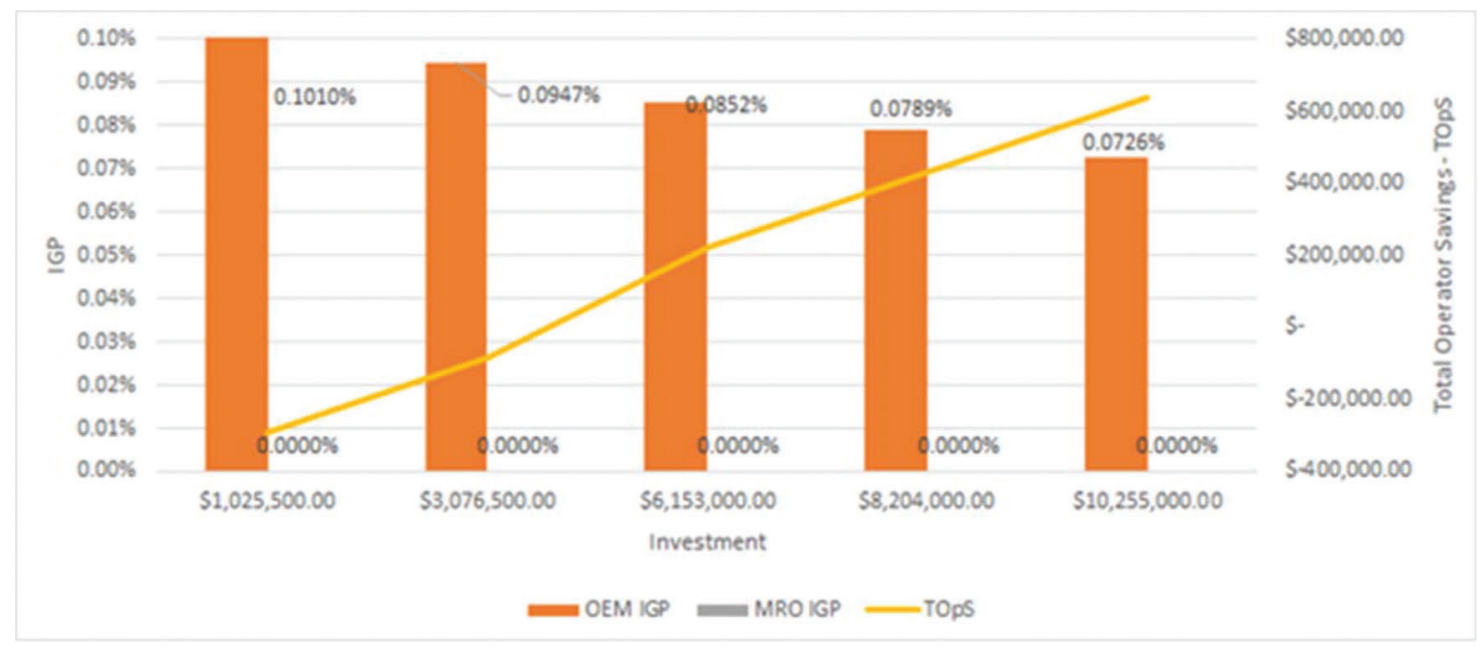

Figure 4. PSS1 impact on GP versus total operator savings (50\% investment from OEM and 50\% investment from MRO firm).

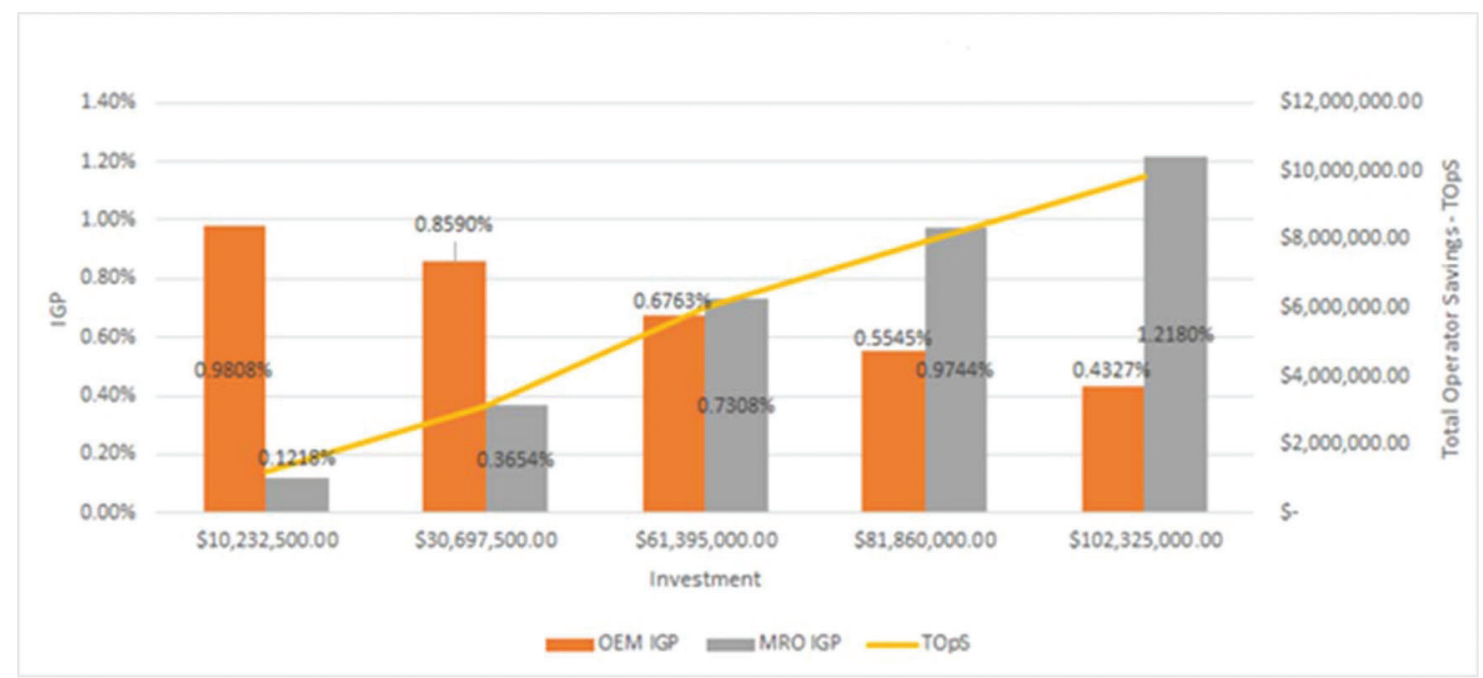

Figure 5. PSS2 impact on GP versus total operator savings (100\% investment from OEM). 


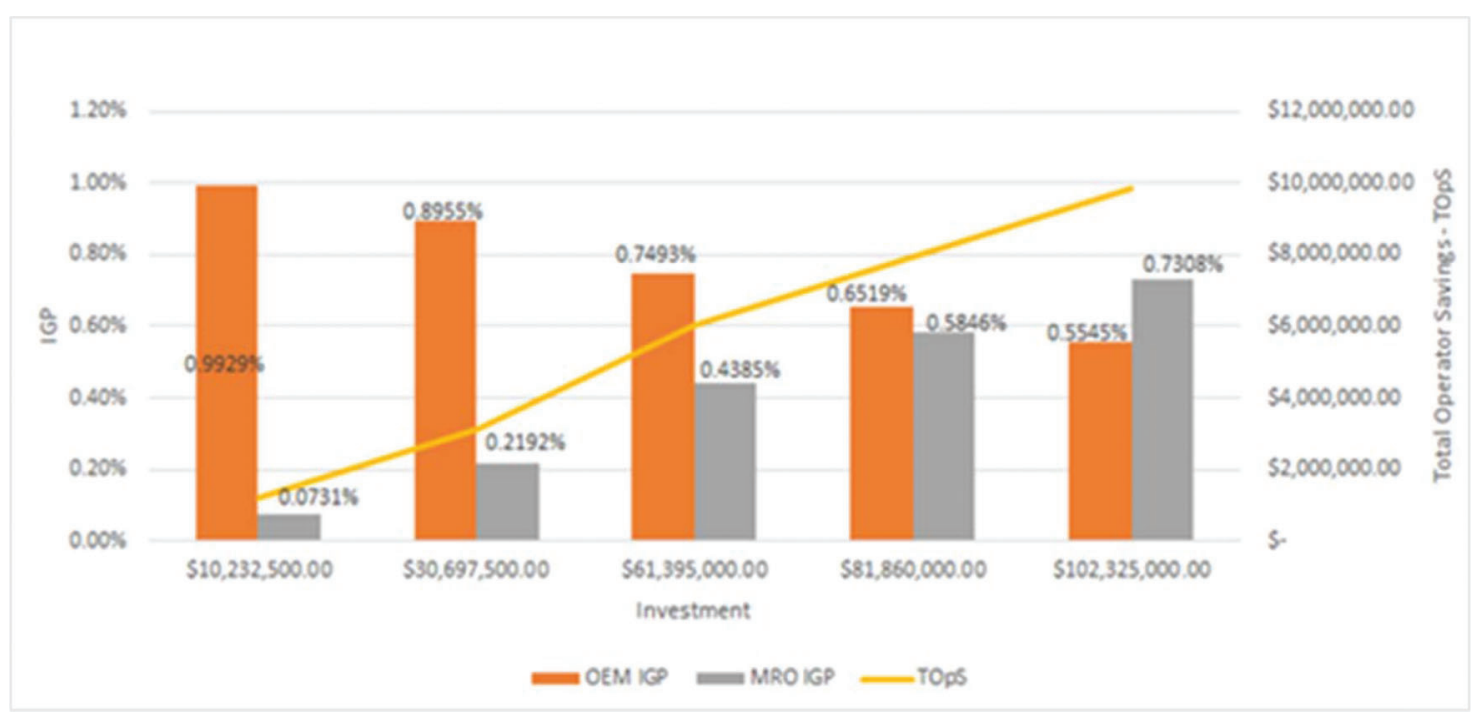

Figure 6. PSS2 impact on GP versus total operator savings ( $80 \%$ investment from OEM and $20 \%$ investment from MRO firm).

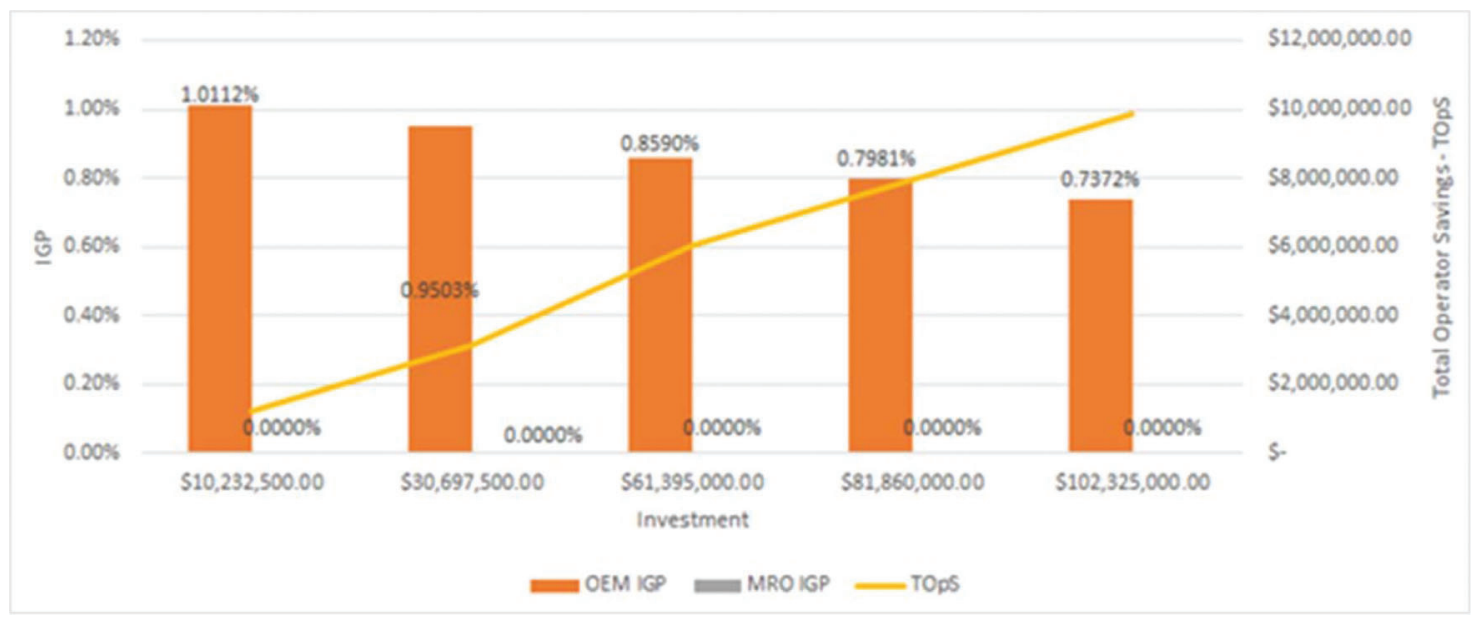

Figure 7. PSS2 impact on GP versus total operator savings (50\% investment from OEM and 50\% investment from MRO firm).

3. Investments lower than $\$ 3 \mathrm{M}$ tend not to promote savings for operators.

4. A small investment $(0.09 \%)$ made by the OEM would promote significant savings to both MRO and operators.

\section{Financial Impact of Different Levels of Investment on Operator Savings}

This analysis consists of a simulation where all the required resources are available except one. Thus, all investment variables are fixed to a $0 \%$ investment gap, except the one to be tested. For the selected variable, five different values (ranging from 20 to $100 \%$ ) are assigned in order to verify how a variation of the investment in the related resource will impact operator's savings with aircraft maintenance (TOpS).

\section{Impact Caused by Lack of Investment on Product Data}

Variations on related investments have no impact on operators' savings since the procurement and purchasing time to acquire this sort of resource does not significantly impact the TAT of the maintenance service.

\section{Impact Caused by Lack of Investment on Spare Parts}

Variations on operators' related maintenance costs are quantified for different levels of investments on spare parts. The obtained results are depicted in Figures 8 and 9 for PSS1 and PSS2, respectively. It should be noted that in both PSS configurations, the investment gap on consumable parts causes no impact on operators' savings as this type of resource can be bought during the maintenance service execution without increasing the TAT due to its short logistics time. Conversely, heavy expendable parts present the longest acquisition lead time; therefore, the shortage of this type of resource causes a higher impact on TOpS than any other spare parts variable. Comparing results from PSS1 one PSS2, it can be observed that the variables behave similarly; however, in configuration two, $T O p S$ does not decrease as abruptly as in configuration one. 


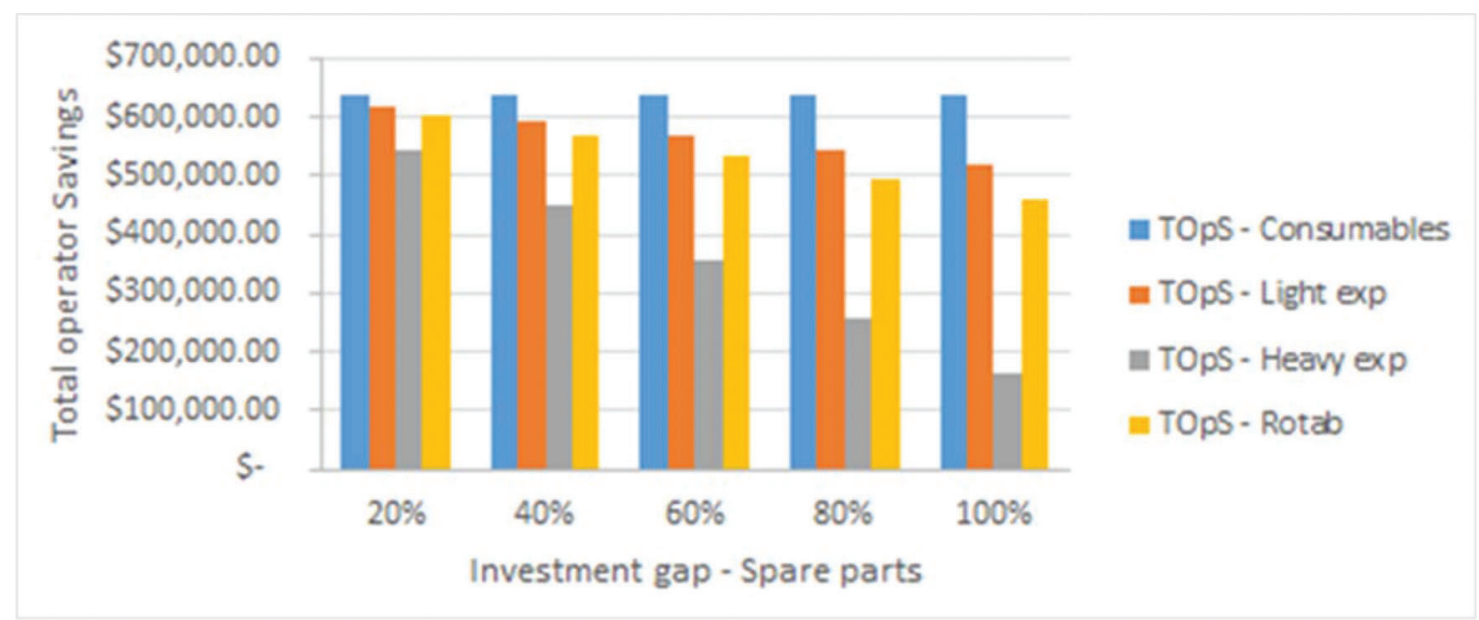

Figure 8. PSS1 total operator savings versus investment gap (spare parts).

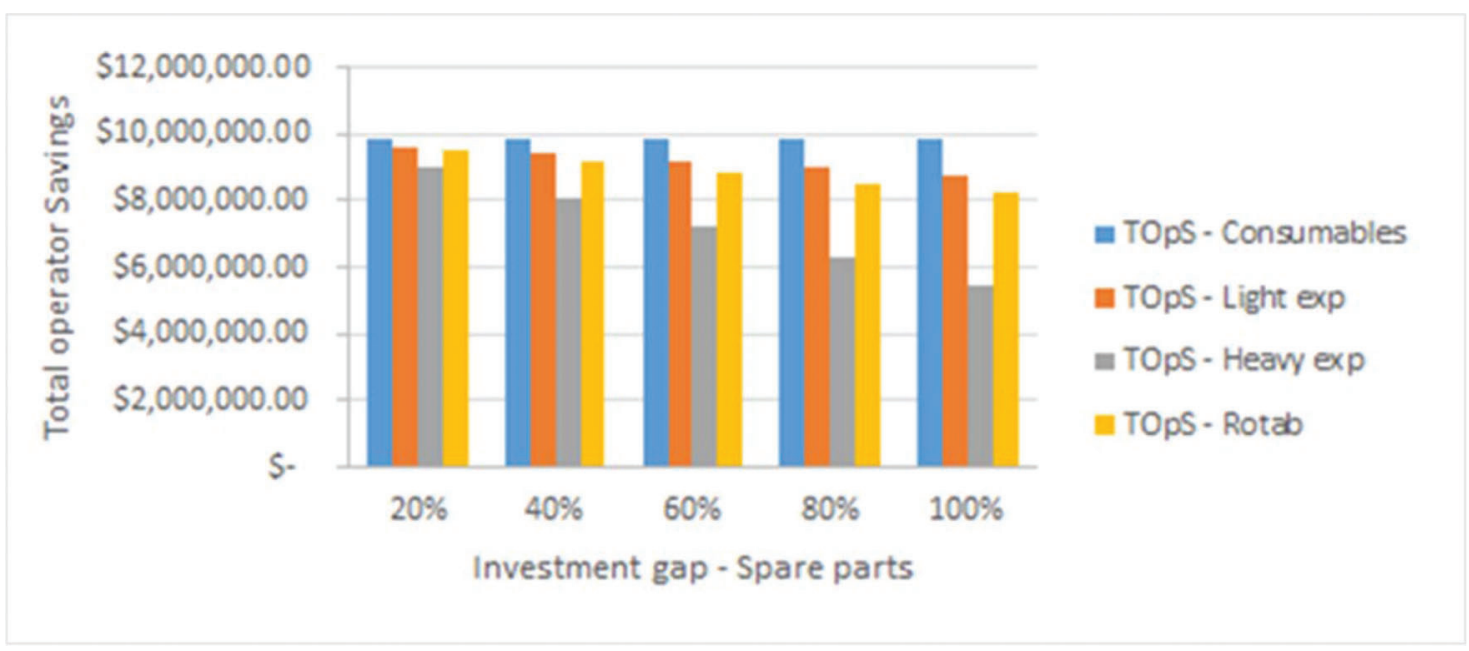

Figure 9. PSS2 total operator savings versus investment gap (spare parts).

For instance, TOpS-Rotab decreases $23 \%$ in PSS1 when varying the investment gap from 20 to $100 \%$, but in PSS2 the $T O p S-$ Rotab variation is only $13 \%$. For $T O p S$ Heavyexp that difference is even more evident: $70 \%$ in configuration one against $39 \%$ in configuration two. These results show that smaller operators are more sensitive to resource availability variation than larger operators.

\section{Impact Caused by Lack of Investment on Tooling}

Tooling variables present behavior similar to that of the spare parts variables. For both PSS configurations (see Figures 10 and 11 for PSS1 and PSS2, respectively), operators' savings decrease with decreasing investments in tooling resources. The lower the resource availability, the higher the risk of TAT increase, representing losses to operators. However, in configuration two, TOpS decreases at a lower rate than it decreases in configuration one. For instance, TOpS-Testsets decreases $60 \%$ in configuration one when varying the investment gap from 20 to $100 \%$, but in configuration two, the TOpS-Testsets variation is only $34 \%$. These results reinforce the thesis that smaller operators are more sensitive to resource availability variation than larger operators.

\section{Impact Caused by Lack of Investment on Training}

Lack of training negatively impacts productivity and leads to TAT increase, resulting in a negative effect on $T O p S$. However, if compared with other resources such as test sets or heavy expendable parts, the impact of lack of training on total operator savings is less significant. According to Figure 12, variation from a 20 to $100 \%$ gap in investments related to training will result in a $\$ 160,000$ impact on TOpS for PSS1 and \$1.5M impact for PSS2.

\section{Impact Caused by Combined Effects}

The previous numerical investigations demonstrate how each investment variable impacts the total operators' savings individually. However, when the effect of low investments on resources that are dependent on each other is combined, the impact on operators' savings may increase. For instance, investment variables related to "installation drawings" and "light expendable parts" individually have no (or very low) 


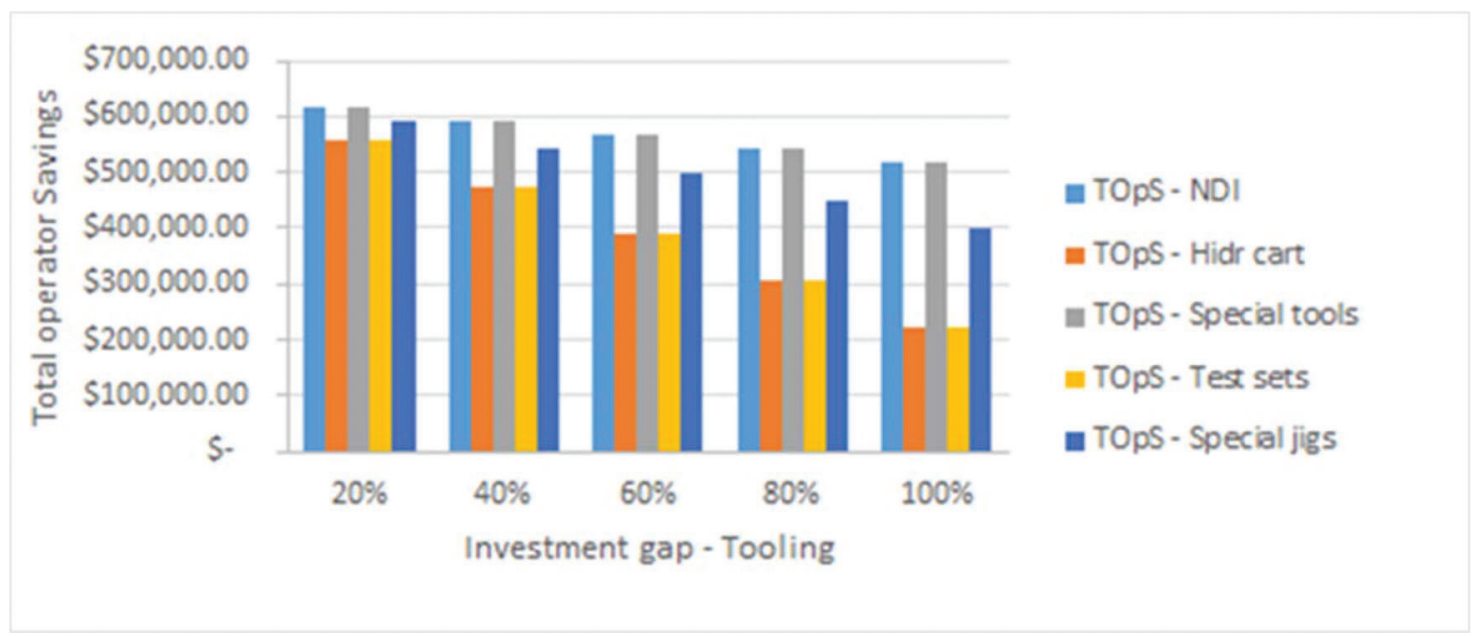

Figure 10. PSS1 total operator savings versus investment gap (tooling).

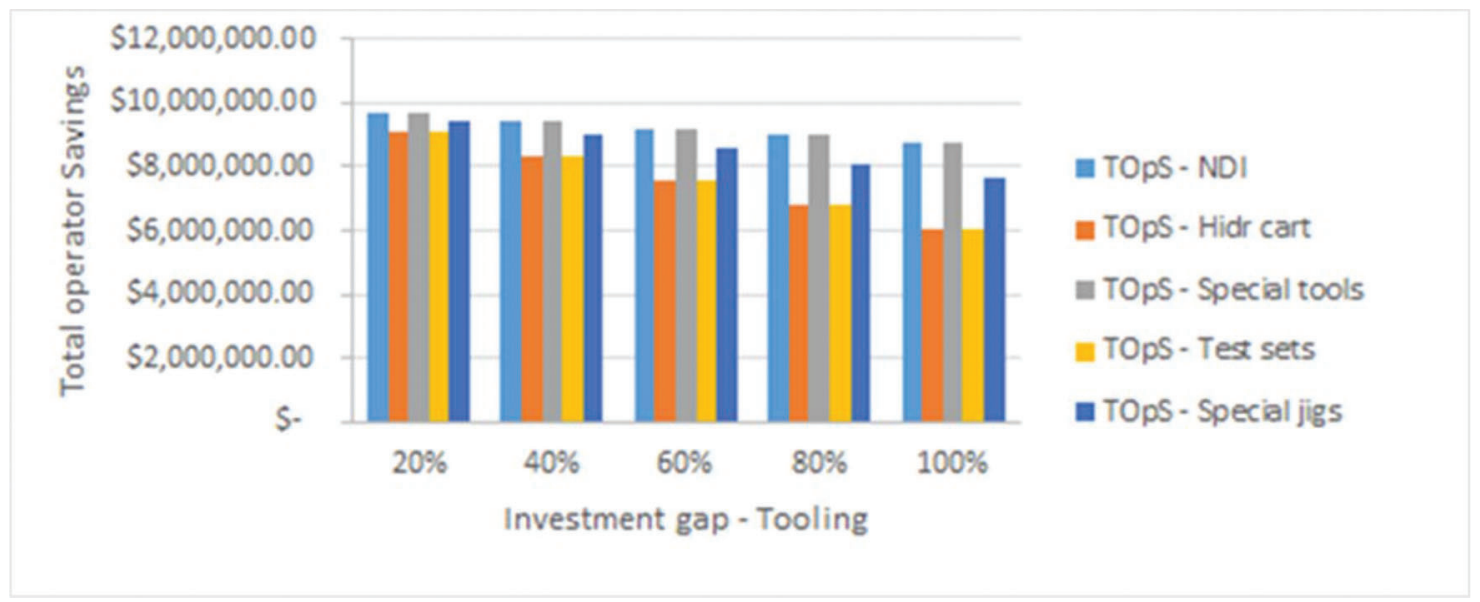

Figure 11. PSS2 total operator savings versus investment gap (tooling).



Figure 12. Total operator savings versus investment gap (training).

impact on $T O p S$, but if combined, the impact on TOpS becomes as high as the impact produced by heavy expendable parts shortage. This occurs due to the existing dependency relation between these two resources; installation drawings call up light expendable parts, so if an installation drawing is not available during maintenance execution, then the related task is interrupted while the drawing is ordered and acquired. Eventually, as that drawing becomes 
ready for use, it is possible that a specific part called up on it may not be available in the warehouse, requiring other purchasing and logistics processes. Thus, the sum of the acquisition lead times of the two resources will cause a combined impact on maintenance service TAT. In the developed model, resources that present a dependency relationship are installation drawings with light expendable parts, fabrication drawings with heavy expendable parts, CMMs with rotable parts, SBs with light expendable parts, and NDI equipment with heavy expendable parts. Figure 13 depicts the impact of three different combinations on PSS1:

1) Installation drawings and light expendable parts.

2) NDI and heavy expendable parts.

3) Fabrication drawings and heavy expendable parts.

Individually, low investments on NDI do not produce a significant impact on $T O p S$; however, the combination of investment gaps on NDI and heavy expendable parts does generate an impact on TOpS that is higher than the one produced alone by short investments on test sets, for instance. It is interesting to note that investment gaps above $80 \%$ in combined fabrication drawings and heavy expendable parts result in financial loss to operators.

\section{Effect of Older Aircraft Fleets}

The proposed quantitative model has also been tested for two more configurations where the average B737NG fleet age is considered to be 15 years old. The size of the stakeholders in PSS configuration three is the same as it is in PSS configuration two, and the size in PSS configuration four is the same as PSS configuration one.

This numerical investigation aims at assessing whether the proposed collaborative business model would still be economically viable for older fleets where investments in operational resources are higher, TATs are longer (see Figure 14), and aircraft are expected to present not only a higher rate of defects, but also more complex problems during execution of heavy checks.

The same three investment scenarios are considered:

1) The OEM makes $100 \%$ of the PSS required investments.

2) The OEM makes $50 \%$ of the PSS required investments and the MRO firm invests the other $50 \%$. Similar to the younger aircraft case, the MRO firm's IGP is always $0 \%$ as the impact on its GP is calculated as the difference between investments made by the OEM and investments made by the MRO.

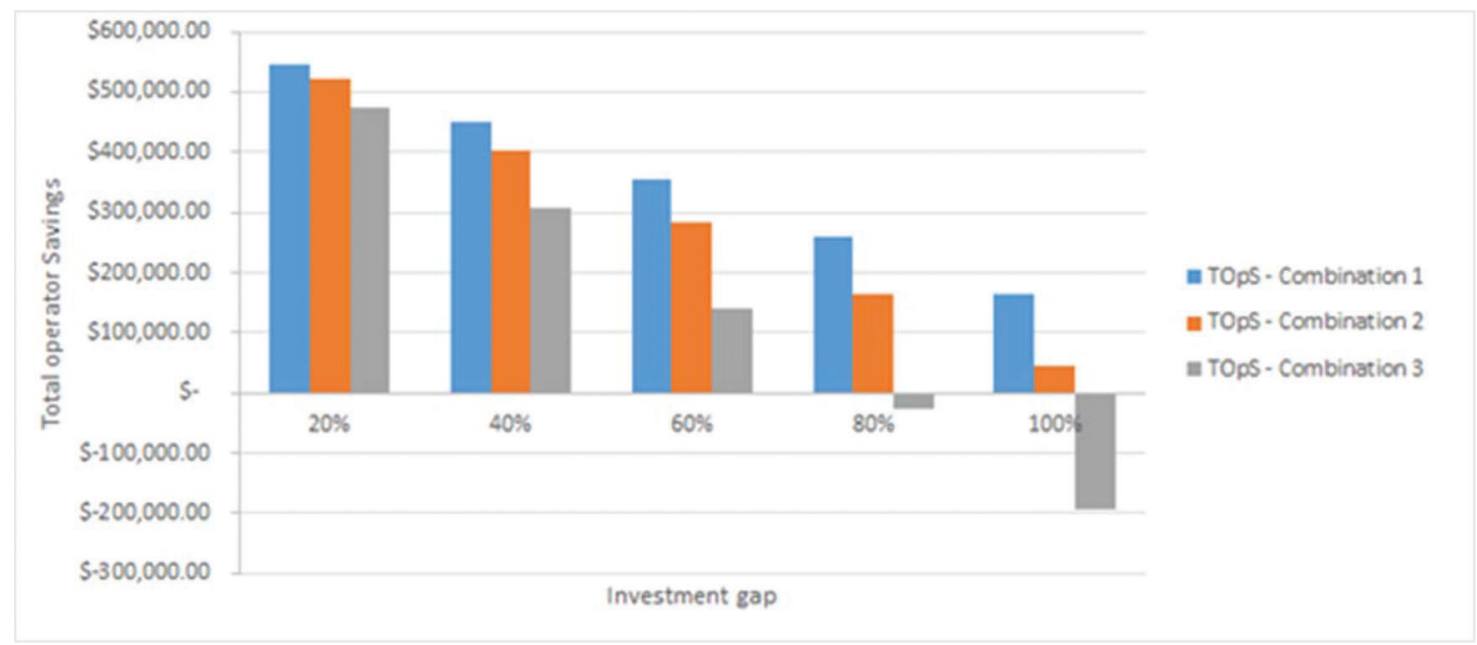

Figure 13. PSS1 total operator savings versus combined investment gaps.

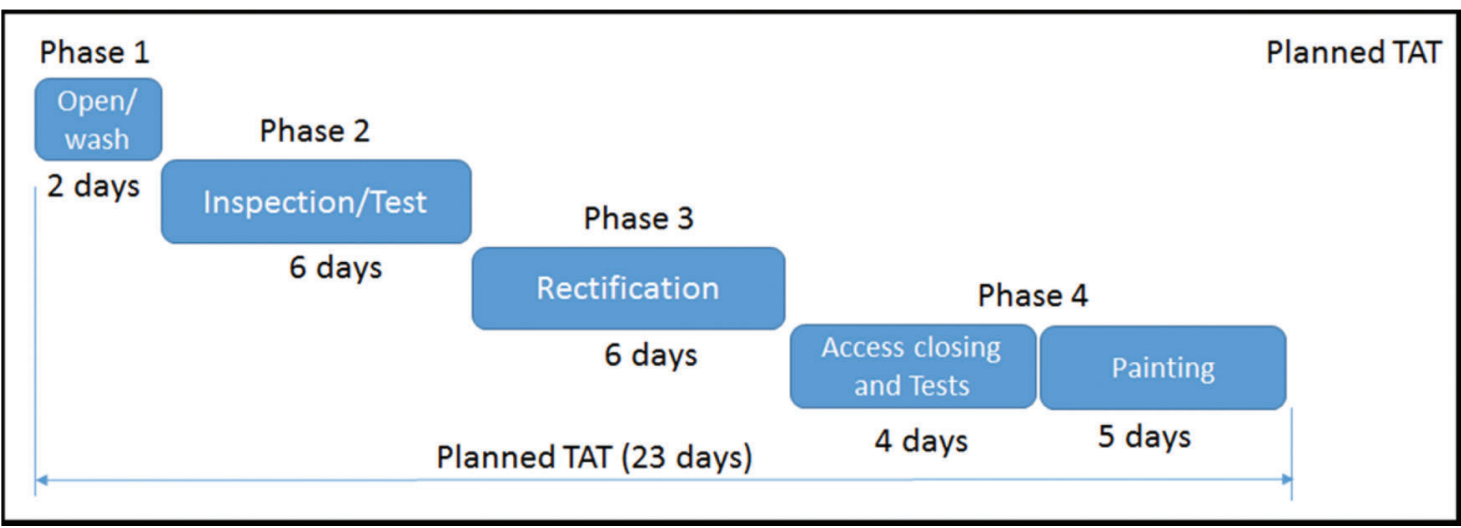

Figure 14. Planned TAT for older aircraft. 
3) The OEM makes $80 \%$ of the PSS required investments and the MRO firm invests the remaining $20 \%$.

However, the overall investments required for older aircraft are assumed to be $50 \%$ higher than for the younger airplanes. The obtained results are depicted in Figures 15-20.
Comparing results obtained for the older fleet (PSS3 and PSS4) with the ones from PSS1 and PSS2, it seems that older aircraft imply a higher risk to the manufacturer as negative values of IGP can be observed (see Figures 15-20).

Figures 18 and 19, when compared respectively with Figures 2 and 3, demonstrate that in configurations where

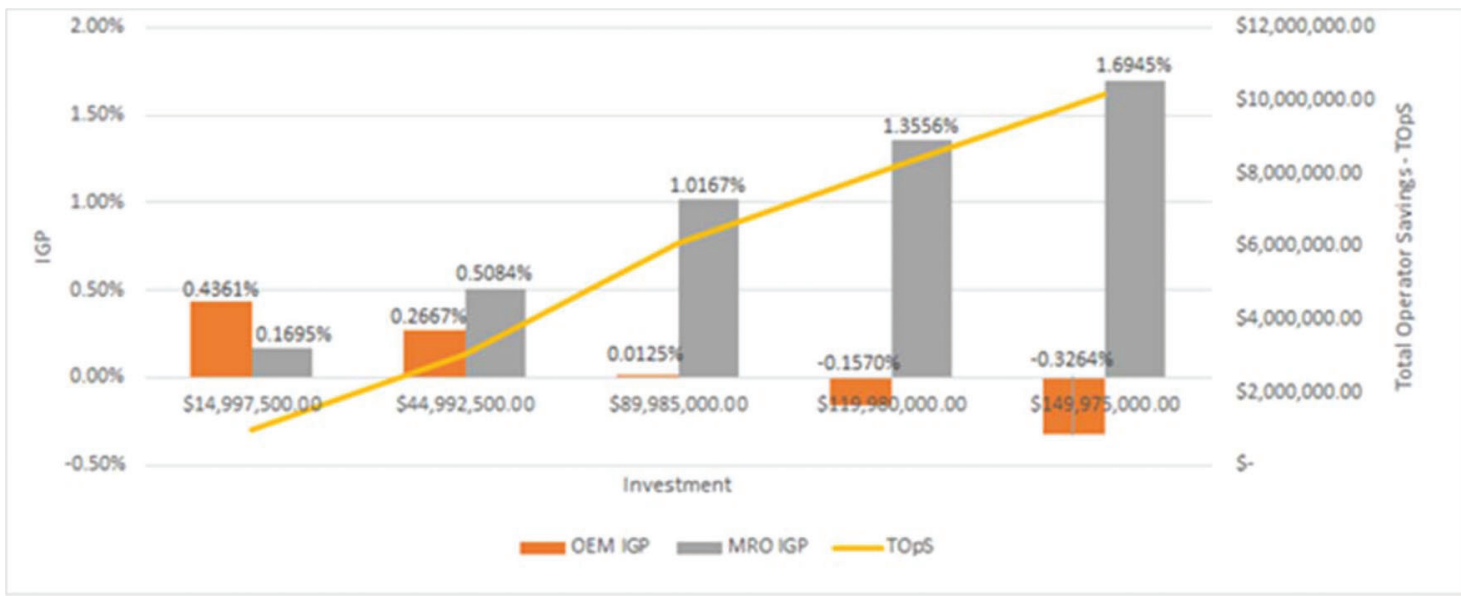

Figure 15. PSS3 impact on GP versus total operator savings (100\% investment from OEM).

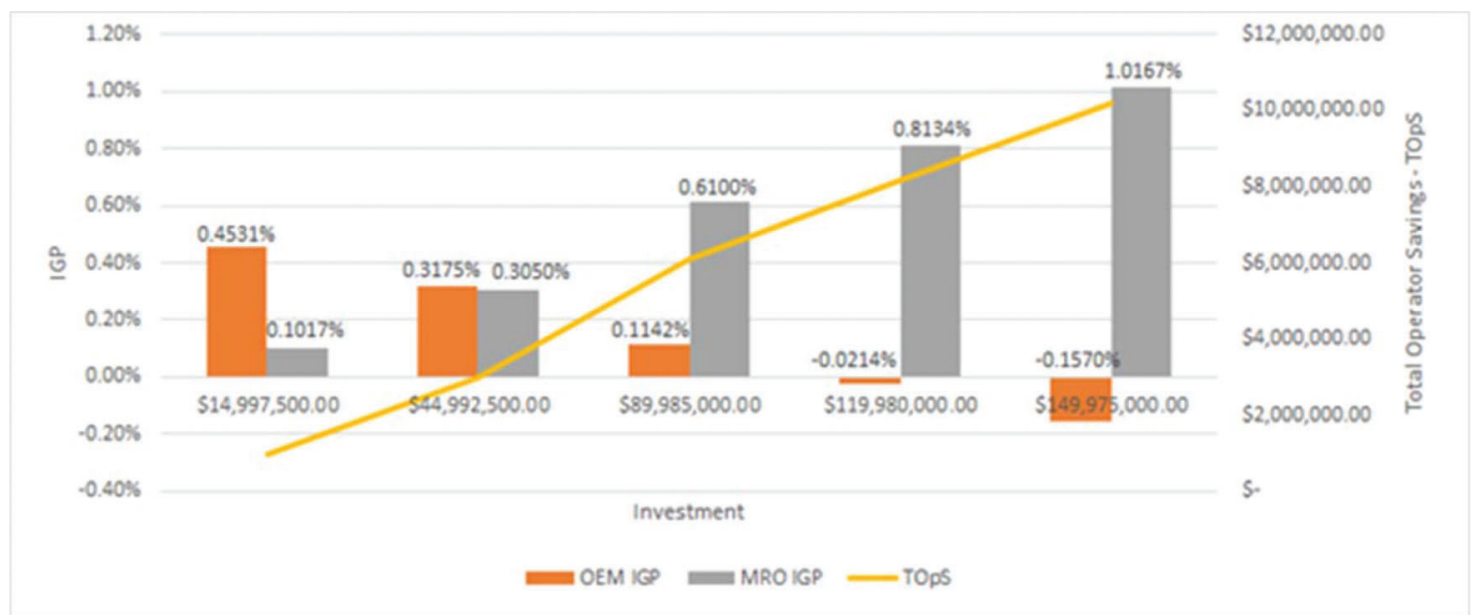

Figure 16. PSS3 impact on GP versus total operator savings ( $80 \%$ investment from OEM and $20 \%$ investment from MRO firm).

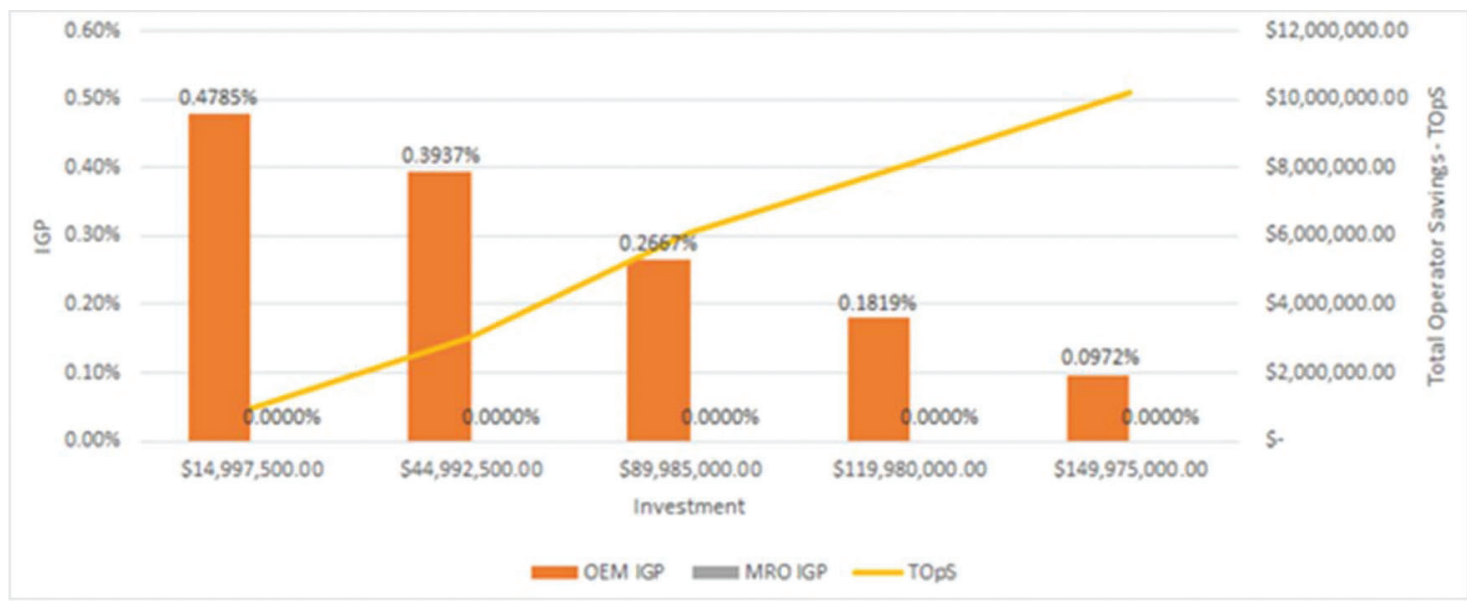

Figure 17. PSS3 impact on GP versus total operator savings (shared investments of 50\% from OEM and 50\% from MRO firm). 


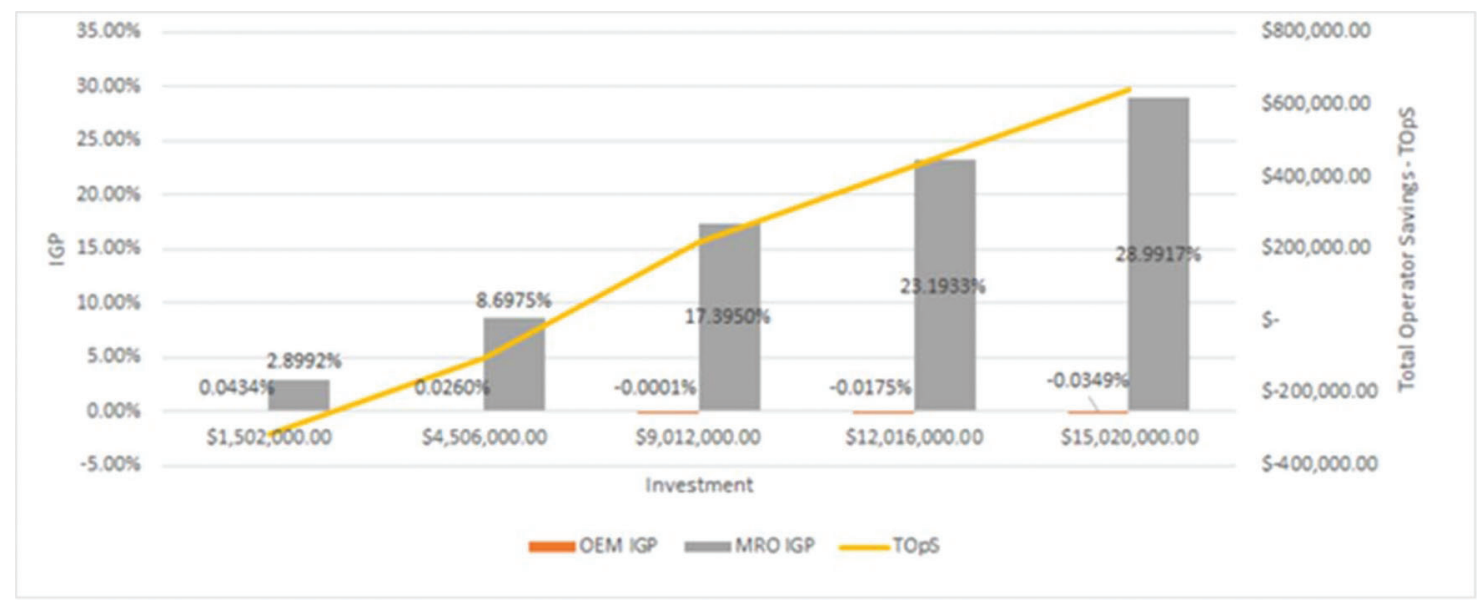

Figure 18. PSS4 impact on GP versus total operator savings (100\% investment from OEM).

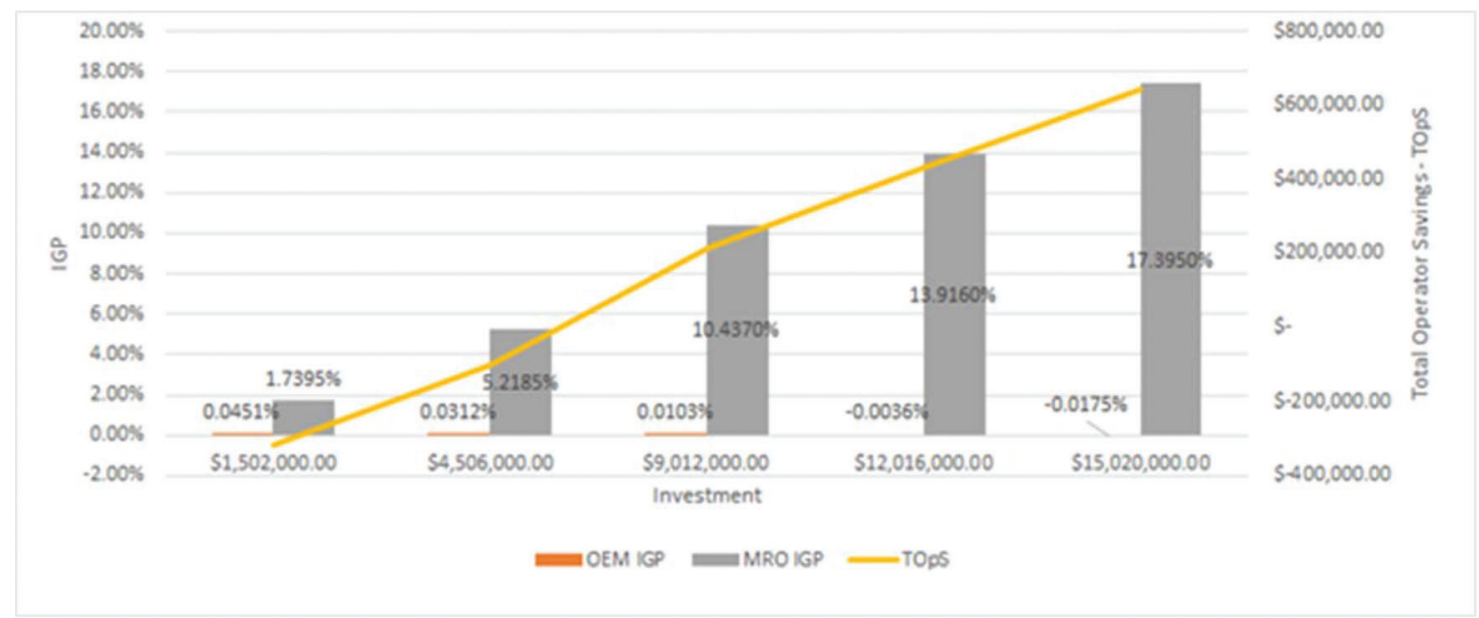

Figure 19. PSS4 impact on GP versus total operator savings (80\% investment from OEM and 20\% investment from MRO firm).

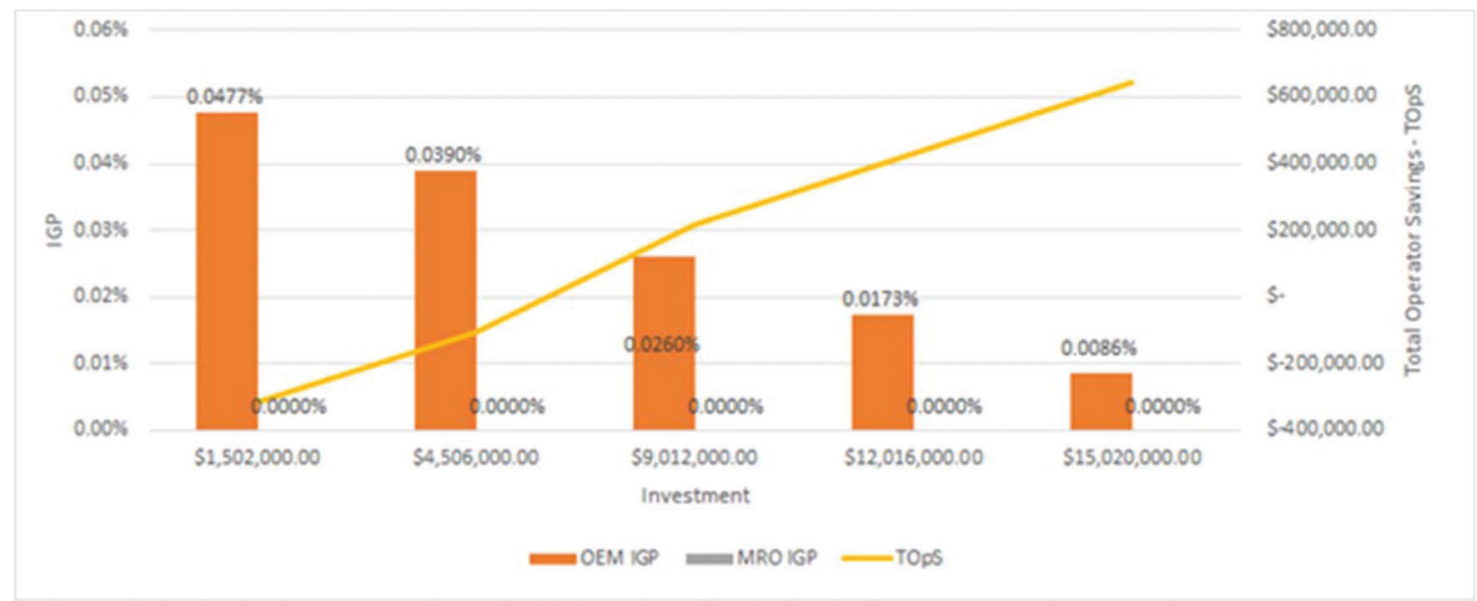

Figure 20. PSS4 impact on GP versus total operator savings (shared investments of 50\% from OEM and 50\% from MRO firm).

MRO firms are smaller than OEMs (PSS1 and PSS4), investments made by the OEM present low negative impact on its GP, but a significant positive impact on the MRO firm's GP as well as on operators' savings.

\section{Discussion}

Table 9 provides a summary to ease comparison between the investigated configurations. Return on investment (ROI) 
Table 9

Summary of investigated configurations.

\begin{tabular}{|c|c|c|c|c|c|c|}
\hline Investment scenario & OEM investment & $\begin{array}{l}\text { OEM's GP } \\
\text { increase }\end{array}$ & $\begin{array}{l}\text { MRO's GP } \\
\text { increase }\end{array}$ & $\begin{array}{c}\text { ROI for OEM } \\
\text { (years) }\end{array}$ & Operator savings & $\begin{array}{c}\text { Operator savings } \\
\text { per aircraft }\end{array}$ \\
\hline \multicolumn{7}{|l|}{ PSS1 } \\
\hline $80 \%$ OEM, $20 \%$ MRO & $\$ 4,800,000$ & $0.07 \%$ & $7.00 \%$ & 6.5 & $\$ 225,000$ & $\$ 18,750$ \\
\hline $50 \%$ OEM, $50 \%$ MRO & $\$ 3,000,000$ & $0.08 \%$ & $0.00 \%$ & 3.5 & $\$ 225,000$ & $\$ 18,750$ \\
\hline $80 \%$ OEM, $20 \%$ MRO & $\$ 2,400,000$ & $0.09 \%$ & $3.79 \%$ & 2.7 & $-\$ 85,000$ & $-\$ 7,083$ \\
\hline $100 \%$ OEM & $\$ 6,100,000$ & $0.07 \%$ & $12.60 \%$ & 8.7 & $\$ 225,000$ & $\$ 18,750$ \\
\hline $50 \%$ OEM, $50 \%$ MRO & $\$ 5,100,000$ & $0.07 \%$ & $0.00 \%$ & 7 & $\$ 639,000$ & $\$ 53,250$ \\
\hline \multicolumn{7}{|l|}{ PSS2 } \\
\hline $80 \%$ OEM, $20 \%$ MRO & $\$ 49,000,000$ & $0.75 \%$ & $0.43 \%$ & 6.5 & $\$ 6,000,000$ & $\$ 50,000$ \\
\hline $50 \%$ OEM, $50 \%$ MRO & $\$ 30,000,000$ & $0.86 \%$ & $0.00 \%$ & 3.5 & $\$ 6,000,000$ & $\$ 50,000$ \\
\hline $50 \%$ OEM,50\% MRO & $\$ 15,000,000$ & $0.95 \%$ & $0.00 \%$ & 1.6 & $\$ 3,141,000$ & $\$ 26,175$ \\
\hline $80 \%$ OEM, $20 \%$ MRO & $\$ 24,000,000$ & $0.89 \%$ & $0.22 \%$ & 2.7 & $\$ 3,100,000$ & $\$ 25,833$ \\
\hline $100 \%$ OEM & $\$ 61,000,000$ & $0.67 \%$ & $0.73 \%$ & 9.1 & $\$ 6,000,000$ & $\$ 50,000$ \\
\hline $50 \%$ OEM, $50 \%$ MRO & $\$ 51,000,000$ & $0.73 \%$ & $0.00 \%$ & 7.0 & $\$ 9,800,000$ & $\$ 81,667$ \\
\hline \multicolumn{7}{|l|}{ PSS3 } \\
\hline $80 \%$ OEM, $20 \%$ MRO & $\$ 72,000,000$ & $0.11 \%$ & $0.61 \%$ & 65.5 & $\$ 6,000,000$ & $\$ 50,000$ \\
\hline $80 \%$ OEM, $20 \%$ MRO & $\$ 12,000,000$ & $0.45 \%$ & $0.10 \%$ & 2.7 & $\$ 970,000$ & $\$ 8,083$ \\
\hline $50 \%$ OEM, $50 \%$ MRO & $\$ 45,000,000$ & $0.27 \%$ & $0.00 \%$ & 16.7 & $\$ 6,000,000$ & $\$ 50,000$ \\
\hline $80 \%$ OEM, $20 \%$ MRO & $\$ 36,000,000$ & $0.32 \%$ & $0.30 \%$ & 11.3 & $\$ 3,000,000$ & $\$ 25,000$ \\
\hline $100 \%$ OEM & $\$ 15,000,000$ & $0.44 \%$ & $0.17 \%$ & 3.4 & $\$ 970,000$ & $\$ 8,083$ \\
\hline $100 \%$ OEM & $\$ 45,000,000$ & $0.27 \%$ & $0.50 \%$ & 16.7 & $\$ 3,000,000$ & $\$ 25,000$ \\
\hline $50 \%$ OEM, $50 \%$ MRO & $\$ 7,500,000$ & $0.48 \%$ & $0.00 \%$ & 1.6 & $\$ 970,000$ & $\$ 8,083$ \\
\hline $50 \%$ OEM, $50 \%$ MRO & $\$ 22,000,000$ & $0.39 \%$ & $0.00 \%$ & 5.6 & $\$ 3,000,000$ & $\$ 25,000$ \\
\hline \multicolumn{7}{|l|}{ PSS4 } \\
\hline $80 \%$ OEM, $20 \%$ MRO & $\$ 7,200,000$ & $0.01 \%$ & $10.40 \%$ & 72.0 & $\$ 216,000$ & $\$ 1,800$ \\
\hline $50 \%$ OEM, $50 \%$ MRO & $\$ 750,000$ & $0.05 \%$ & $0.00 \%$ & 1.6 & $-\$ 315,000$ & $-\$ 2,625$ \\
\hline $80 \%$ OEM, $20 \%$ MRO & $\$ 3,600,000$ & $0.03 \%$ & $5.21 \%$ & 12.0 & $-\$ 103,000$ & $-\$ 858$ \\
\hline $100 \%$ OEM & $\$ 4,500,000$ & $0.03 \%$ & $8.69 \%$ & 17.3 & $-\$ 103,000$ & $-\$ 858$ \\
\hline $50 \%$ OEM, $50 \%$ MRO & $\$ 6,000,000$ & $0.02 \%$ & $0.00 \%$ & 35.3 & $\$ 429,000$ & $\$ 3,575$ \\
\hline
\end{tabular}

for OEMs is calculated for each alternative to indicate economic viability from the manufacturer's perspective. ROI is obtained for each scenario by calculating the ratio between the OEM investment and the annual increase in the OEM's GP. Additionally, operator savings per aircraft per year are reported so that gains to operators can be compared regardless of their size.

In the PSS1 scenario where the OEM is responsible for $80 \%$ of all investments, a contribution made by the OEM of $\$ 4.8 \mathrm{M}$ (or $0.48 \%$ of its GP) would generate an annual positive financial return of $0.07 \%$ of its GP, thus paying its investment back in about 6.5 years. Notwithstanding, what appears to be a modest result to the OEM is revealed as a significant positive impact of 7\% on the MRO's GP and annual operator savings of $\$ 225 \mathrm{k}$, which represents a very positive impact on the maintenance budget of an operator with a small fleet (twelve aircraft). Taking into consideration a different investment scenario (OEM participating with $50 \%$ of the total investments in PSS1), an investment of $\$ 3 \mathrm{M}$ made by the OEM (and total PSS1 investment of $\$ 6 \mathrm{M}$ ) could be returned in a shorter period of time (3.5 years) while promoting the same amount of savings to the operator $(\$ 225 \mathrm{k})$ and no significant impact on the MRO's GP. From the OEM's standpoint, this investment scenario is of higher interest than the one described first, whereas both deliver similar levels of value to the operator.
Moreover, higher annual savings $(\$ 639 k)$ could be promoted for operators if an investment of $\$ 5.1 \mathrm{M}$ is made by the OEM and the total PSS1 investment is $\$ 10.2 \mathrm{M}$. It would entail a less interesting financial return option to OEM (payback in 7 years), but an almost three times better result for the operator.

Regarding the results related to configuration PSS3, in the scenario where $100 \%$ of investments are made by the OEM, investments above $\$ 90 \mathrm{M}$ imply negative values of IGP $P_{\text {OEM }}$ to the OEM. Lower investment amounts produce a positive impact on the OEM's GP, but not necessarily an adequate financial return. For instance, an investment of $\$ 45 \mathrm{M}$ would produce a positive impact on the OEM's GP $(0.27 \%)$ but a poor ROI (16 years).

All three investment scenarios related to PSS3 only produce reasonable financial results to the OEM at lower investment levels, such as in the $80 / 20$ scenario, where an investment of $\$ 12 \mathrm{M}$ would promote a ROI of 2.7 years. Consequently, moderate value added is delivered to the operator (only $\$ 8,000$ of annual savings per aircraft). Annual savings of $\$ 8,000$ represent a moderate/weak result to operators.

By comparing the stakeholder characteristics of the four PSSs, it can be stated that PSS1 corresponds to PSS4 with regards to their composition of stakeholders (large OEM, small MRO, and small operator) and PSS2 corresponds to 
PSS3 (large OEM, large MRO, and large operator). A pairto-pair comparison reveals that aircraft age exerts critical influence in PSSs involving small MROs and small operators. Results related to PSS4 demonstrate that alternatives of all investment scenarios are either economically unfeasible to the OEM or decrease value to the operator. Conversely, PSS1's younger fleet promotes better financial results to stakeholders as observed in its 50/50 investment scenario, where a $\$ 3 \mathrm{M}$ OEM investment produces a ROI of 3.5 years and annual savings to the operator of $\$ 18,750$ per aircraft.

The aircraft age factor also poses challenges to the PSS2 and PSS3 configurations, but with lower intensity. When comparing results related to these two PSSs, it can be concluded that both configurations produce viable alternatives, but PSS3 would deliver reduced added value to operators compared to PSS2.

In addition, a comparison between PSS1 and PSS2 shows that results vary linearly with the size of the stakeholders (GP and aircraft number). Larger MROs present higher GP, but require proportional investment amounts in operational resources. In a PSS where the OEM is much larger than the MRO, an irrelevant amount invested by the OEM may represent the enabling factor for the MRO's economic feasibility. A fundamental observation when comparing both PSS configurations is that a partnership between an OEM and a large MRO would ask for a large investment that would be concentrated in only one geographical region, while if an OEM invests this same amount of financial resources in several smaller MROs around the globe, a deeper level of global in-service support capillarity could be reached, promoting fleet coverage for a larger geographical area.

The assessment of impacts on total operator savings by investment gaps with different combined variables shows a possible case of an unfeasible PSS where the level of investment for key resources is too low, implying negative results to operators (combination three). In 2015, a real case of an unbalanced and poorly designed PSS resulted in an unsuccessful business. An airframe OEM in Brazil certified two small MROs in the same region, but did so without following a collaborative approach to facilitate their operation or taking into account the fact that the regional market was not large enough to provide maintenance service for two MROs. An unfeasible investment scenario for both MROs resulted because expensive acquired operational resources were underutilized, resulting in financial losses to those companies and low service levels to operators.

In summary, the higher the total amount invested in the PSS, the more added value is produced to operators. However, an adequate balance between the amounts invested by OEMs and MROs must be assessed in terms of financial return against the value delivered to the operator. There will be cases where good profits can be achieved by OEMs and MROs with moderate value provided to the operator and other cases where the OEM and MRO may not obtain significant financial results, but the PSS's design could promote high value added to the operator.

Therefore, the results presented in this section demonstrate that designing business models for airframe maintenance services is a tricky activity. The success of a business model between OEMs, MROs, and operators is strongly dependent on the balance between the economic and financial relations of these enterprises. A sustainable PSS business model results from the adequate combination of companies in terms of size and production capacity, the age of the fleet, and the willingness and availability to invest in the PSS. The numerical results presented in Table 9 reveal that variations in these characteristics are determinant for either the success or failure of the PSS, leading to the conclusion that these business decisions must be precise, with a very limited margin for mistakes. Two other characteristics of companies within the aerospace and aviation market reinforce the need for accurate business decisions related to service design: (1) the wide majority of these enterprises have been historically operating within low economical margins and (2) decisions related to design of service strategies are often not as quantitative as they should be. Additionally, manufacturers often assess financial viability of a strategy only under their perspective, not taking into consideration the MRO's specific needs. Combining these characteristics with the results presented in Table 9, it can be concluded that there is a need for a more systematic and quantitative means of supporting decision makers in aerospace service design.

In such a context, this research presents a quantitative tool to contribute to this critical decision-making process. The tool represents an original solution to the aerospace and aviation industries, aiding in the selection of effective and sustainable PSS design alternatives.

\section{Conclusion}

This paper exercises the model presented in its companion (Part I) to investigate numerically the impact of different scenarios of aviation MRO firms and airframe OEM collaboration based on the exchange of value-adding resources. In the proposed collaborative business strategy, OEMs must support MRO firms by increasing the availability of critical resources to the maintenance providers, such as parts, tools, equipment, product data, and training.

A practical example of that type of support could be a local or regional OEM-owned warehouse being strategically located close to an MRO firm, or even inside their facilities, in order to ensure that operator demand is met in a timely fashion. Access to technical training and product data can also be facilitated in many forms by OEMs to MRO firms as an operational means of the proposed collaborative business model.

Certainly, investments to be made by the OEM may seem to create a negative impact on its financial results. 
Notwithstanding, the obtained results demonstrate that, in certain investment scenarios, this impact can be compensated by potential benefits to OEMs, such as access to in-service data or enhanced parts demand forecast.

Main business relationships between MRO firms, OEMs, and operators are captured and applied as an innovative tool that fosters a collaborative mindset to support the decision-making process.

\section{Limitations and Future Work}

It is important to highlight some limitations related to the presented model, such as that it only allows an analysis of business models that involve only one type of aircraft and heavy check at the time. Future studies are encouraged to enhance this quantitative model so as to support multiple types of aircrafts and heavy checks. Despite that limitation, the current model can be applied to cases where the OEM has multiple investments in MROs globally, as well as to cases where the MRO receives multiple investments from different OEMs. Each combination of OEM and MRO would be treated as a specific PSS configuration with a particular set of parameters that could be assessed individually.

Additional effort is also recommended to evolve this quantitative collaboration method to an optimization model. This would enable both an assessment of more complex investment scenarios with an increased number of resources, and the identification of partnerships that maximize the GP of OEMs and MROs, as well as savings to operators.

The collaborative approach proposed herein between airframe OEMs and MRO enterprises could be extended to manufacturers of aerospace components (engines, landing gears, auxiliary power units, electronic modules, etc.) and their respective independent service network.

Further studies could also be developed using datasets collected over a period of time for various MROs and OEMs in other jurisdictions to validate how acquisition of in-service data can reduce maintenance intervals due to increased product reliability.

\section{Acknowledgments}

The first author acknowledges CAPES, the Brazilian Foundation of the Ministry of Education, and the McGill Faculty of Engineering Doctoral Award for providing the required financial support that enabled the development of this work. This financial support does not constitute an endorsement of the opinions expressed in this work.

\section{References}

Ali, K. M., \& McLoughlin, B. (2012). Benefits of optimizing maintenance intervals. Proceedings from MCC '12: 8th IATA Maintenance Cost Conference, Atlanta, GA.

Canaday, H. (2016, January 8). Big data: Finding the MRO nuggets. Aviation Week \& Space Technology.

Cohen, M. A., \& Wille, J. H. (2006). Implications for service parts management in the rapidly changing aviation MRO market. Retrieved from https://pdfs.semanticscholar.org/de28/fa9215540e4b1aa99bbe9525264 861b93000.pdf

Dinero, D. (2005). Training within industry: The foundation of lean (HAR/COM ed.). Productivity Press.

Federal Aviation Administration. (2003). Practices and perspectives in outsourcing aircraft maintenance (OAR publication no. DOT/FAA/ AR02/122). Retrieved from https://www.faa.gov/about/initiatives/ maintenance_hf/library/documents/media/human_factors_maintenance/ ar02-122.pdf

Goncalves, C. D., \& Kokkolaras, M. (2017). Modelling the relationship between aviation original equipment manufacturers and maintenance, repair, and overhaul enterprises from a product-service system perspective. Proceedings from ICED '17: The 21st International Conference on Engineering Design, vol. 3: Product, services and systems design, Vancouver, Canada.

IATA. (2015). Guidance material and best practices for inventory management [PDF file]. Retrieved from https://www.iata.org/ whatwedo/workgroups/Documents/MCTF/inventory-mgmt-2ndedition.pdf

Kurita, Y., Uei, K., Kimita, K., \& Shimomura, Y. (2013). A method for supporting service cost analysis. In Y. Shimomura \& K. Kimita (Eds.), The philosopher's stone for sustainability (pp. 517-522). Berlin, Germany: Springer-Verlag. doi.org/10.1007/978-3-642-32847-3

McLoughlin, B., Doulatshahi, F., \& Onorati, J. (2011). Improving maintenance programs through statistical analysis. Boeing AeroMagazine (Issue 43, Quarter 3), 13-15. Retrieved from https://www.boeing. com/commercial/aeromagazine/articles/2011_q3/pdfs/AERO_2011_ Q3.pdf

PIPAME. (2010). Maintenance et réparation aéronautique. Retrieved from https://www.entreprises.gouv.fr/files/files/directions_services/ etudes-et-statistiques/etudes/aeronautique_maintenance/aeronautique_ maintenance.pdf

Rosenberg, B. (2004, April 19). Everybody's doing it; Airline maintenance strategies are diverse, but all include an element of outsourcing. Aviation Week \& Space Technology, p. 68.

SAS Institute Inc. (2012). How can we reduce inventory costs while increasing aircraft fleet readiness? [PDF file] Retrieved from https:// www.sas.com/content/dam/SAS/en_us/doc/solutionbrief/defense-andaerospace-reduce-inventory-costs-105547.pdf

Vieira, D. R., \& Loures, P. L. (2016). Maintenance, repair and overhaul (MRO) fundamentals and strategies: An aeronautical industry overview. International Journal of Computer Applications, 135(12), 21-29. https://pdfs.semanticscholar.org/d4c5/ae856718a7d3ac58dc375be2e57 bade34fff.pdf

Wallin, J. (2013). Developing capability for product-service system innovation (Doctoral thesis). Retrieved from http://publications.lib. chalmers.se/records/fulltext/187502/187502.pdf 